OPEN ACCESS

Vol. 3 No. 1: 10-17

Tahun 2019

Artikel penelitian 圆
Jurnal Alewatililestari

E-ISSN: 2598-8204

https://ojs.umrah.ac.id/index.php/akuatiklestari

DOI : https://doi.org/10.31629/akuatiklestari.v3i1.936

\title{
Pengaruh Laju Sedimentasi Terhadap Kerapatan Lamun di Perairan Beloreng Kelurahan Tembeling Tanjung Kabupaten Bintan
}

\author{
Effect of Sedimentation Rate on Seagrass Density in Beloreng Waters, Tembeling Tanjung Village, \\ Kabupaten Bintan
}

\section{Riky Fernando $^{1} \bowtie$, Winny Retna Melani ${ }^{1}$, Dedy Kurniawan ${ }^{1}$}

1 Manajemen Sumberdaya Perairan, Fakultas Ilmu Kelautan dan Perikanan, Universitas Maritim Raja Ali Haji, Tanjungpinang, Indonesia 29111

$\square$ Info Artikel:

Diterima: 28 Januari 2019

Revisi: 20 Februari 2019

Disetujui: 20 Oktober 2019

Dipublikasi: 30 November 2019

\section{[1] Keyword:}

Bintan, Kerapatan Lamun, Laju Sedimentasi, Perairan Beloreng

\section{$\square$ Penulis Korespondensi:}

Riky Fernando

Manajemen Sumberdaya Perairan Fakultas Ilmu Kelautan dan Perikanan Universitas Maritim Raja Ali Haji Tanjungpinang 29111 Email: fernandoriky206@gmail.com

\begin{abstract}
ABSTRAK. Tujuan penelitian ini adalah untuk mengetahui tingkat kerapatan lamun, laju sedimentasi dan pengaruh laju sedimentasi terhadap kerapatan lamun di Perairan Beloreng Kelurahan Tembeling Tanjung Kabupaten Bintan. Penelitian ini dilakukan dengan metode survei sebanyak 30 titik menggunakan plot berukuran $1 \times 1$ meter dan sediment trap. Hasil penelitian ditemukan 5 jenis lamun yaitu, Thalassia hemprichii, Enhalus acoroides, Cymodocea rontundata, Halodule uninervis, dan Halophila decipiens dengan kerapatan berkategori rapat. Laju sedimentasi dengan nilai total sebesar $0,3668\left(\mathrm{~g} / \mathrm{cm}^{2} /\right.$ hari) dengan nilai rata-rata selama sebulan yang mengalami kenaikan setiap minggunya, serta laju volume sedimentasi dengan nilai total $0,1778\left(\mathrm{ml} / \mathrm{cm}^{2} /\right.$ hari) dan memiliki nilai rata-rata perbulan yang sama. Hasil analisis pengaruh laju sedimentasi terhadap kerapatan lamun di Perairan Beloreng Kelurahan Tembeling Tanjung Kabupaten Bintan dengan hasil 87\% kerapatan lamun dipengaruhi oleh laju sedimentasi, dengan hubungan antar variabel bersifat sangat kuat.
\end{abstract}

\begin{abstract}
The purpose of this study was to determine the density level of seagrass, sedimentation rates and the effect of sedimentation rates on seagrass density in Beloreng waters, Tembeling Tanjung, Bintan Regency. This research was conducted with a survey method of 30 points using a $1 \times 1$ meter plot and a sediment trap. The results of the study found 5 types of seagrass, namely, Thalassia hemprichii, Enhalus acoroides, Cymodocea rontundata, Halodule uninervis, Halophila decipiens with meeting density, and obtained sedimentation rate results with a total value of $0.3668\left(\mathrm{~g} / \mathrm{cm}^{2} /\right.$ day) with an average value during a month that increases every week, and the rate of sedimentation volume with a total value of $0.1778\left(\mathrm{ml} / \mathrm{cm}^{2} /\right.$ day $)$ and has the same monthly average value. The results of theinfluence of the sedimentation rate on the density of seagrasses in Beloreng Waters, Tanjung Tembeling Village, Bintan Regency with $87 \%$ yield influenced by seagrass density, and the relationship between variables is very strong.
\end{abstract}

\section{䁣 How to cite this article:}

Fernando, R., Melani, R,W., \& Kurniawan, D. (2019). Pengaruh Laju Sedimentasi Terhadap Kerapatan Lamun di Perairan Beloreng Kelurahan Tembeling Tanjung Kabupaten Bintan. Jurnal Akuatiklestari, 3(1): 10-17. https://doi.org/10.31629/akuatiklestari.v3i1.936

\section{PENDAHULUAN}

Wilayah Provinsi Kepulauan Riau terdiri dari gugusan pulau-pulau besar dan kecil yang terletak satu dengan lainnya yang dihubungkan dengan perairan. Provinsi Kepulauan Riau merupakan wilayah kepulauan seluas 425.214,67 $\mathrm{km}^{2}$, terdiri dari wilayah daratan seluas $9.982,88 \mathrm{~km}^{2}$ dan wilayah lautan seluas $415.231,79 \mathrm{~km}^{2}$. Kabupaten Bintan memiliki rentang wilayah pantai yang panjang yaitu sekitar $966,54 \mathrm{~km}^{2}$ garis pantai serta wilayah laut yang sangat luas yaitu $86.398,33 \mathrm{~km}^{2}$ atau 98,51\% dari total wilayah Kabupaten Bintan. Kondisi ini menyebabkan wilayah Kabupaten Bintan memiliki potensi pembangunan ekonomi laut dan perikanan yang sangat besar dan beragam. Kabupaten Bintan memiliki sumberdaya ekosistem lamun dengan luas 2.918,36 Ha, ekosistem mangrove seluas $8.895 .87 \mathrm{Ha}$, dan ekosistem terumbu karang yang memiliki luasan 9.085,33 Ha (DKP Bintan, 2011; Mariani et al., 2019).

Perairan Laut Beloreng Kelurahan Tembeling Tanjung adalah perairan yang sangat penting bagi masyarakat Tembeling, karena masyarakat Tembeling sebagian adalah nelayan yang banyak mencari ikan di Perairan Beloreng (Putri et al., 2018). Perairan ini memiliki sebaran vegetasi lamun yang cukup luas selain itu kegiatan yang terjadi di 
sekitar perairan ini memiliki dampak yang negatif bagi kualitas lingkungan perairan laut Tembeling. Di sekitaran perairan berdirinya bekas pertambangan bauksit yang memberikan limbah ke dalam perairan, sehingga dari kegiatan bekas pertambangan sangat berdampak bagi perairan sehingga menjadikan perairan tersebut keruh.

Menurut Simon et al. (2013), lamun (seagrass) adalah tumbuhan berbunga (angiospermae) yang sudah sepenuhnya menyesuaikan diri hidup terbenam di dalam laut. Lamun memiliki fungsi dalam menunjang kehidupan dan perkembangan jasad hidup di laut dangkal yaitu sebagai produsen primer, sebagai habitat biota, sebagai penangkap sedimen, sebagai pendaur zat hara. Menurut Hidayat et al. (2014) menyebutkan bahwa laju sedimentasi adalah banyaknya massa sedimen yang terangkat melalui satu satuan luas dalam setiap satuan waktu. Laju pergerakan dan penyebaran sedimen dalam perairan adalah fungsi dari karakteristik sedimen-sedimen yang meliputi ukuran dan densitas, serta karakteristik dari aliran terutama kecepatan aliran dan temperatur. Perairan Beloreng Kelurahan Tembeling Tanjung memiliki potensi sumberdaya alam yang berpeluang besar untuk dimanfaatkan lebih lanjut, kurangnya informasi mengenai kondisi lamun dan adanya bekas kegiatan pertambangan bauksit di sekitaran Perairan Tembeling yang menyebabkan perairan keruh ataupun sedimen dasar yang naik kepermukaan perairan akibat sedimentasi.

Tujuan Penelitian ini adalah mengetahui tingkat kerapatan lamun, mengetahui laju sedimentasi, dan mengetahui pengaruh laju sedimentasi terhadap kerapatan lamun di Perairan Beloreng Kelurahan Tembeling Tanjung Kabupaten Bintan. Manfaat penelitian ini adalah memberikan informasi mengenai kondisi ekosistem lamun yang terkait pada proses pengaruh dari laju sedimentasi terhadap kerapatan lamun di Perairan Beloreng Kelurahan Tembeling Tanjung Kabupaten Bintan, serta sebagai acuan upaya pengelolaan kawasan oleh pihak terkait, dan memberikan gambaran bagi akademisi untuk penelitian lanjutan.

\section{BAHAN DAN METODE}

\subsection{Waktu dan tempat}

Penelitian dilaksanakan pada bulan Maret 2018 - Januari 2019 di Perairan Beloreng Kelurahan Tembeling Tanjung Kabupaten Bintan, yang meliputi survey lokasi, pengambilan data, pengamatan tegakan lamun, analisa sampel, pengolahan data, analisa data serta penyusunan laporan hasil

\subsection{Alat dan bahan}

Alat yang digunakan pada penelitian ini yaitu : Plot ukuran lxl meter digunakan untuk mengukur tingkat kerapatan lamun; Sediment Trap digunakan untuk menambat sedimen; Buku Identifikasi digunakan untuk mengidentifikasi lamun; Multitester digunakan untuk mengukur suhu dan DO; Refractometer digunakan untuk mengukur salinitas; layangan arus digunakan untuk mengukur kecepatan arus; GPS (global Positioning System) untuk menentukan titik koordinat; Secchi Disc digunakan untuk melihat kecerahan; gelas ukur $25 \mathrm{ml}$ digunakan untuk menghitung volume sedimen; $\mathrm{pH}$ meter digunakan untuk mengukur $\mathrm{pH}$; timbangan digunakan untuk mengukur berat substrat; oven digunakan untuk mengeringkan sampel sedimen; kamera digital digunakan untuk mendokumentasikan saat penelitian; kacamata renang digunakan untuk mengamati saat penelitian berlangsung; serta tali dan pemberat digunakan untuk mengukur kedalaman;

Bahan yang digunakan dalam penelitian ini antara lain sampel lamun dan sedimen sebagai objek yang akan diamati; kertas label sebagai penanda sampel penelitian; dan alat tulis menulis untuk mencatat data di lapangan.

\subsection{Prosedur penelitian}

\subsubsection{Pengambilan Sampel Lamun}

Tegakan lamun dihitung dengan menggunakan kuadrat transek yang berukuran 1 meter x 1 meter yang masih dibagi-bagi lagi menjadi 25 sub petak, berukuran $20 \mathrm{~cm}$ x $20 \mathrm{~cm}$. Transek diletakkan di daerah padang lamun yang mempunyai kerapatan yang lebat dan yang jarang agar data dapat terwakili sehingga data akurat. Untuk caranya adalah transek kuadrat diletakkan pada titik yang telah ditentukan berdasarkan random sampling dan dihitung kerapatannya pada tiap plot transek (Nursanti et al., 2013).

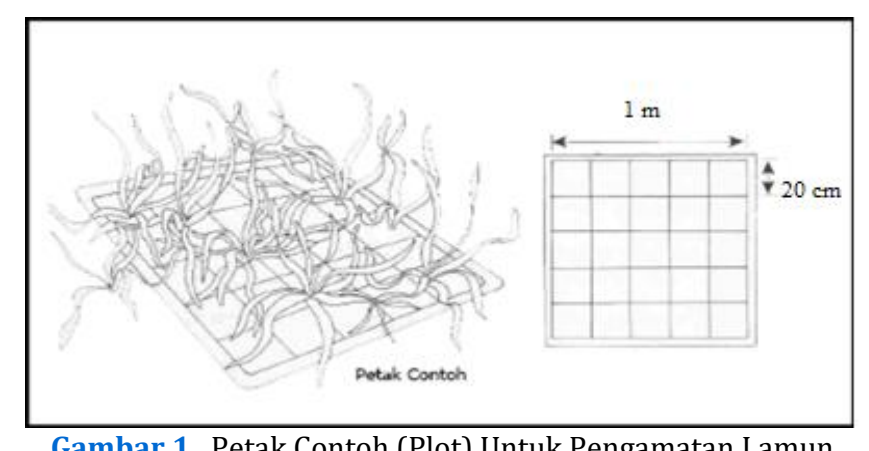

Gambar 1. Petak Contoh (Plot) Untuk Pengamatan Lamun

(Sumber: Modifikasi KEPMEN LH No. 200 Tahun 2004) 


\subsubsection{Pengambilan Data Laju sedimentasi}

Menurut Hidayat et al. (2014), penambat sedimen dibuat dari pipa paralon dengan tinggi $12 \mathrm{~cm}$ dengan diameter $5 \mathrm{~cm}$ sebanyak 3 buah pipa paralon untuk setiap sediment trap dan diberi jaring penutup $\pm 2,28$ mm juga dilengkapi dengan besi patok, tinggi besi $100 \mathrm{~cm}$ agar mudah ditancap di dasar perairan dan tidak mudah untuk terbawa arus. Jarak antara dasar perairan dan pipa paralon sedimen trap $20 \mathrm{~cm}$. Jangan sampai sediment trap tidak pada posisi berdiri karena jika dalam posisi miring, maka sedimen tidak bisa ditangkap dan sedimen yang sudah dalam tabung penangkap akan terlepas ke perairan,

Lama waktu sediment trap diletakan di lokasi penelitian terhitung dari tujuan penelitian yang akan dilakukan. Secara umum bisa dilakukan selama 4 minggu dan setiap l minggu diangkat kemudian dihitung jumlah sedimen yang terakumulasi, Hasil perhitungan akan didapat berat sedimen dan volume sedimentasi yang terakumulasi per-waktu akumulasi dan pada perangkap sedimen ini juga dipasang pelampung tanda agar letak dari penambat sedimen mudah untuk diketahui.

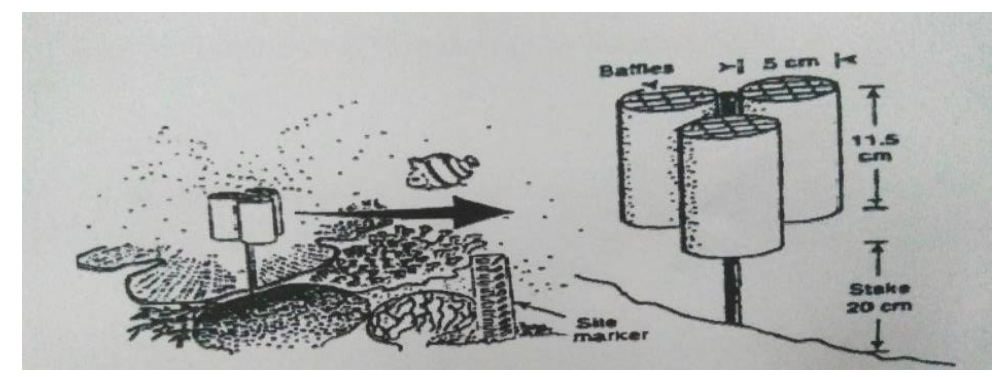

Gambar 2. Sediment Trap

\subsection{Teknik Pengumpulan Data}

\section{Analisis Kerapatan Lamun}

Kerapatan Jenis (Ki), yaitu jumlah total individu jenis dalam suatu unit area yang diukur (Azkab 1999).

Dimana:

$$
\mathrm{Ki}=\frac{\mathrm{ni}}{\mathrm{A}}
$$

$\mathrm{Ki} \quad=$ Kerapatan Jenis $\left(\mathrm{ind} / \mathrm{m}^{2}\right)$

ni $\quad=$ Jumlah Total Individu (ind)

$\mathrm{A} \quad=$ Luas Area Total Pengambilan Sampel $\left(\mathrm{m}^{2}\right)$

\subsubsection{Analisis Laju Sedimentasi}

Akumulasi sedimen yang dihitung adalah berat sedimen yang terendapkan persatuan luas area per waktu dengan perhitungan dan Akumulasi sedimen dapat dihitung dengan menggunakan rumus perhitungan. Nursanti et al. (2013), sebagai berikut :

$$
\text { Laju Berat Akumulasi }=\frac{w / L}{t}
$$

Keterangan :

Laju Berat Akumulasi $=\left(\mathrm{gram} / \mathrm{cm}^{2} /\right.$ hari $)$

$\mathrm{w}=$ Berat Kering Sedimen (gram)

$\mathrm{L} \quad=$ Luas Penampang Sediment trap $(\mathrm{cm} 2)$

$\mathrm{t}=$ Waktu Pemasangan Sediment trap (hari)

Dan dianalisa Kecepatan akumulasi pada penelitian ini dibedakan menjadi kecepatan volume akumulasi (ml) dan berat akumulasi (gram) persatuan luas permukaan $(\mathrm{cm})$.

$$
\text { Laju Volume Akumulasi }=\frac{v / L}{t}
$$

Keterangan :

Laju Volume Akumulasi $=\left(\mathrm{ml} / \mathrm{cm}^{2} /\right.$ hari $)$

$\mathrm{v} \quad=$ Volume Sedimen $(\mathrm{ml})$

$\mathrm{L} \quad=$ Luas Penampang Sediment trap $\left(\mathrm{cm}^{2}\right)$ 
$\mathrm{t} \quad$ = Waktu Pemasangan Sediment trap (hari)

\subsection{Analisis Data}

Analisis Komponen Laju sedimentasi dan Kerapatan Lamun dengan Parameter Lingkungan

Analisis pengaruh Laju Sedimentasi terhadap Kerapatan Lamun dengan parameter lingkungan dilakukan dengan menggunakan PCA (Principal Component Analysis) bertujuan untuk melihat parameter lingkungan mana yang lebih mempengaruhi Laju sedimentasi dan Kerapatan Lamun dengan menggunakan bantuan aplikasi Minitab.

\section{Analisis Data Pengaruh Laju Sedimentasi Terhadap Kerapatan Lamun}

Analisis regresi linier dapat digunakan untuk mengetahui perubahan pengaruh yang akan terjadi berdasarkan pengaruh yang ada pada periode waktu sebelumnya. untuk mengetahui sejauhmana hubungan dan pengaruh diperkirakan antara kerapatan lamun dengan laju sedimentasi dilakukan rumus regresi linier sederhana, yaitu sebagai berikut :

$$
\mathrm{Y}=\mathrm{a}+\mathrm{bX}
$$

Dimana :

$\mathrm{Y} \quad$ = Subjek variabel terikat yang diprediksi (Laju Sedimentasi)

$\mathrm{X}$ = Subjek Variabel bebas yang mempunyai nilai tertentu (Kerapatan Lamun)

$\mathrm{a} \quad=$ Bilangan konstanta regresi untuk $\mathrm{X}=0$ (nilai $\mathrm{y}$ pada saat $\mathrm{x}$ nol)

$\mathrm{b}$ = Koefisien arah regresi yang menunjukkan angka peningkatan atau penurunan variabel Y bila bertambah atau berkurang 1 Unit.

\section{HASIL DAN PEMBAHASAN}

\subsection{Identifikasi Lamun}

Identifikasi jenis-jenis lamun yang dilakukan pada 30 titik pengamatan di Perairan Beloreng Kelurahan Tembeling Tanjung dijumpai 5 jenis lamun diantaranya yaitu jenis Thalassia hemprichii, Cymodocea rontundata, Enhalus acoroides, Halophila uninervis, dan Halophila decepiens (KEPMEN LH No. 200 Tahun 2004).

\subsection{Komposisi Jenis Lamun}

Komposisi jenis lamun menggambarkan persentase setiap jenis lamun di perairan Beloreng Kelurahan Tembeling Tanjung. Berdasarkan perhitungan komposisi jenisnya didapatkan hasil komposisi jenis lamun yang disajikan pada Gambar 3.

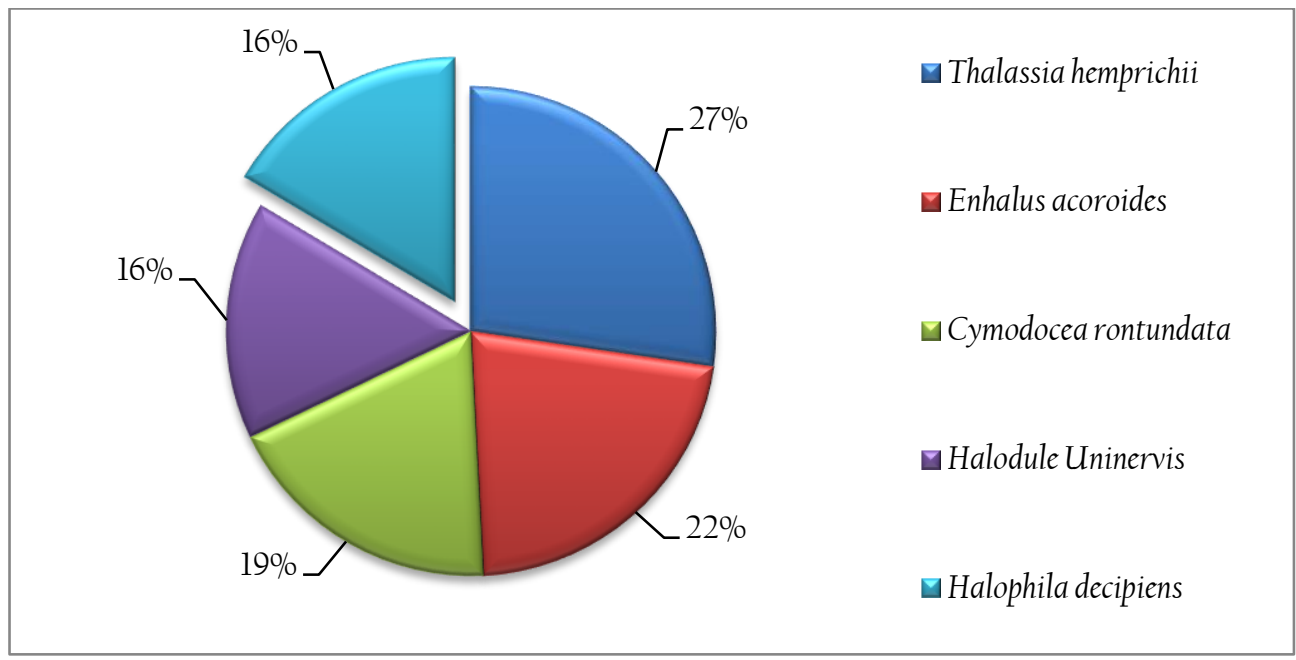

Gambar 3. Komposisi Jenis Lamun

Dari presentase Gambar diatas menunjukkan bahwa jenis Thalassia hemprichii mempunyai presentase tertinggi hingga $27 \%$. Hal ini diduga karena jenis lamun Tihalassa hemprichii memiliki pertahanan diri yang kuat sehingga bisa hidup di perairan terbuka yang kondisi perairannya relatif memiliki arus (Santoso et al., 2018).

Sedangkan komposisi jenis lamun terendah terdapat pada lamun jenis Halodule uninervis sebesar $16 \%$, hal ini diduga karena perairan Beloreng Kelurahan Tembeling Tanjung memiliki substrat yang lumpur berpasir sedikit kerikil, sehingga lamun jenis ini sedikit ditemukan pada semua titik pengamatan. Hal tersebut sesuai dengan pendapat Syukur (2016), yang menyatakan bahwa lamun jenis Halodule uninervis menyukai jenis substrat yang berpasir dan akan membentuk padang lamun yang lebat pada substrat yang berpasir karang. 


\subsection{Parameter Lokasi Penelitian}

Tabel 1. Parameter Lingkungan Perairan

\begin{tabular}{|c|c|c|c|c|c|}
\hline No & Parameter & Satuan & Rata-rata & Baku Mutu* & Jenis \\
\hline & Parameter Fisika & & & & \\
\hline 1 & Suhu & ${ }^{\circ} \mathrm{C}$ & $29,58 \pm 0,337$ & $28-30 *$ & \\
\hline 2 & Salinitas & $\mathrm{o} / \mathrm{oo}$ & $26,97 \pm 1,159$ & $33-34 *$ & \\
\hline 3 & Kecerahan & $\mathrm{m}$ & $1,12 \pm 0,177$ & $>3 *$ & \\
\hline 4 & TSS & $\mathrm{mg} / \mathrm{L}$ & $79,17 \pm 58,962$ & $20^{*}$ & \\
\hline 5 & Kedalaman & $\mathrm{m}$ & $1,31 \pm 0,189$ & - & \\
\hline 6 & $\begin{array}{l}\text { Kecepatan Arus } \\
\text { Parameter Kimia }\end{array}$ & $\mathrm{m} / \mathrm{s}$ & $0,0116 \pm 0,001$ & - & \\
\hline 1 & DO & $\mathrm{mg} / \mathrm{L}$ & $7,49 \pm 0,196$ & $>5^{*}$ & \\
\hline 2 & $\begin{array}{l}\mathrm{pH} \\
\text { Substrat }\end{array}$ & - & $8 \pm 0,486$ & $7-8,5^{*}$ & \\
\hline 1 & Jenis Fraksi & & \multicolumn{2}{|c|}{ Pasir Berlumpur } & $\begin{array}{c}\text { Pasir Hingga } \\
\text { Lumpur }\end{array}$ \\
\hline
\end{tabular}

Sumber : Data Primer

*KEPMEN LH NO.51 Tahun 2004

Pengukuran kualitas perairan dilakukan secara langsung pada saat di lapangan in situ dan di laboratorium. Parameter kualitas air merupakan hal penting yang berpengaruh terhadap variabel-variabel hayati yang diamati selama penelitian. Pada tabel dapat dilihat bahwa parameter lingkungan masih dalam kisaran optimum kondisi perairan.

Pengukuran suhu dilakukan pada pagi hari dengan cuaca yang baik, saat itu perairan sedang mengalami surut. Hasil pengukuran suhu di Perairan Kelurahan Tembeling Tanjung memiliki nilai rata-rata $29,58 \pm 0,33^{\circ} \mathrm{C}$. Pada saat pengukuran suhu optimal berkisar 28,9 hingga $30^{\circ} \mathrm{C}$, menurut baku mutu air laut untuk biota laut, (KEPMEN LH tahun No. 51 tahun 2004).

Pengukuran salinitas dilakukan pagi hari kondisi saat menjelang surut. Hasil pengukuran salinitas di Perairan

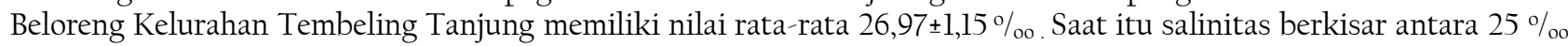
hingga $29 \%$ menunjukkan bahwa salinitas rendah yang disebabkan adanya suplai air tawar melalui aliran sungai yang bermuara ke Perairan Beloreng Kelurahan Tembeling Tanjung yang disebabkan oleh perairan estuari. Kisaran salinitas berdasarkan baku mutu air laut KEPMEN LH No. 51 (2004), menyatakan salinitas optimum untuk baku mutu lamun berkisar antara 33\% - 34\% dan diperbolehkan terjadi perubahan sampai dengan $<5 \%$ salinitas rata-rata musiman.

Pengukuran kecerahan dilakukan saat pasang dengan cuaca yang baik, Hasil pengukuran kecerahan di Perairan Beloreng Kelurahan Tembeling Tanjung memiliki rata-rata nilai kecerahan yang diperoleh pada 30 titik pengamatan yaitu 1,12 $\pm 1,77$ m. Jika mengacu pada KEPMEN LH No. 51 (2004), maka kecerahan yang baik untuk kehidupan biota akuatik adalah > 3 meter, dengan demikian kondisi Perairan Beloreng Kelurahan Tembeling Tanjung memiliki tingkat kecerahan yang rendah. Kecerahan yang rendah mencirikan perairan yang keruh dan akan berdampak pada penetrasi cahaya matahari yang masuk ke perairan (Shaffai, 2011).

Pengukuran Total suspended solid dilakukan pada sore hari dengan cuaca yang baik, saat itu Total suspended solid di Perairan Beloreng Kelurahan Tembeling Tanjung memiliki nilai rata-rata yang diperoleh pada 30 titik pengamatan yaitu 79,17 $( \pm 58,96) \mathrm{mg} /$ l. Jika mengacu pada KEPMEN LH no.5l (2004) menyatakan bahwa TSS melebihi dari ambang batas baku mutu kehidupan lamun karena TSS yang baik untuk kehidupan biota berkisar hingga 20.

Pengukuran kedalaman di perairan Beloreng Kelurahan Tembeling Tanjung memiliki nilai rata-rata $(1,31)( \pm 0,18)$. Hal ini menunjukkan bahwa data kedalaman yang didapatkan di Perairan Beloreng Kelurahan Tembeling Tanjung cocok untuk pertumbuhan lamun. Menurut Azkab (2000), komunitas lamun kebanyakan dapat tumbuh dengan baik pada kedalaman 1-2,5 meter dari permukaan laut Selain itu kedalaman mempunyai hubungan yang erat dengan stratifikasi suhu, kemampuan menembus cahaya, serta zat-zat hara. Kedalaman erat juga kaitannya dengan kecepatan endapan sedimen (densitas). Kecepatan pengendapan sedimen di pengaruhi oleh kedalaman perairan, semakin dalam perairan maka pengendapan juga akan semakin lama menuju dasar, sedangkan semakin dangkal perairan memungkinkan sedimen lebih cepat mengendap ke dasar perairan.

Pengukuran Kecepatan Arus ini dilakukan pada sore hari saat menjelang pasang. Hasil pengukuran kecepatan arus di Perairan Beloreng Kelurahan Tembeling Tanjung dengan nilai rata-rata 0,0116 $\pm 0,0013 \mathrm{~m} / \mathrm{s}$. kecepatan arus saat penelitian berlangsung saat itu memiliki arus yang lambat dengan kisaran 0,0101-0,0152 m/s. Hal ini disebabkan oleh tingginya kerapatan lamun di Perairan Beloreng Kelurahan Tembeling Tanjung (Surbakti, 2012).

Pengukuran Oksigen terlarut dilakukan pada cuaca yang baik, hasil pengukuran oksigen terlarut di Perairan Beloreng Kelurahan Tembeling Tanjung menunjukkan bahwa rata-rata nilai DO yang diperoleh pada 30 titik pengamatan yaitu sebesar 7,49 $\pm 0,196$ mg/L. Mengacu pada KEPMEN LH No. 51 (2004), kandungan Oksigen terlarut (DO) yang sesuai untuk kehidupan organisme akuatik adalah sebesar $>5 \mathrm{mg} / \mathrm{L}$.

Pengukuran derajat keasaman $(\mathrm{pH})$ dilakukan pada cuaca yang baik, hasil pengukuran derajat keasaman $(\mathrm{pH})$ di Perairan Beloreng Kelurahan Tembeling Tanjung menunjukkan bahwa rata-rata nilai pH yang diperoleh pada 30 titik penelitian yaitu sebesar $8 \pm 0,486$. Dengan demikian kondisi derajat keasaman $(\mathrm{pH})$ ini sesuai dengan baku mutu yang 
dianjurkan untuk kehidupan organisme akuatik yang mengacu pada KEPMEN LH No. 51 (2004). Komposisi kerikil 3,2 $\%$, pasir sebesar $45,4 \%$, dan lumpur 51,4\%

\subsection{Laju Sedimentasi Berdasarkan Berat Kering}

Dari hasil penelitian laju sedimentasi selama 4 minggu, setelah melakukan pengovenan dan penimbangan berat endapan sedimen lalu dilakukan perhitungan laju sedimentasi dengan nilai didapatkan nilai rata-rata setiap titik.

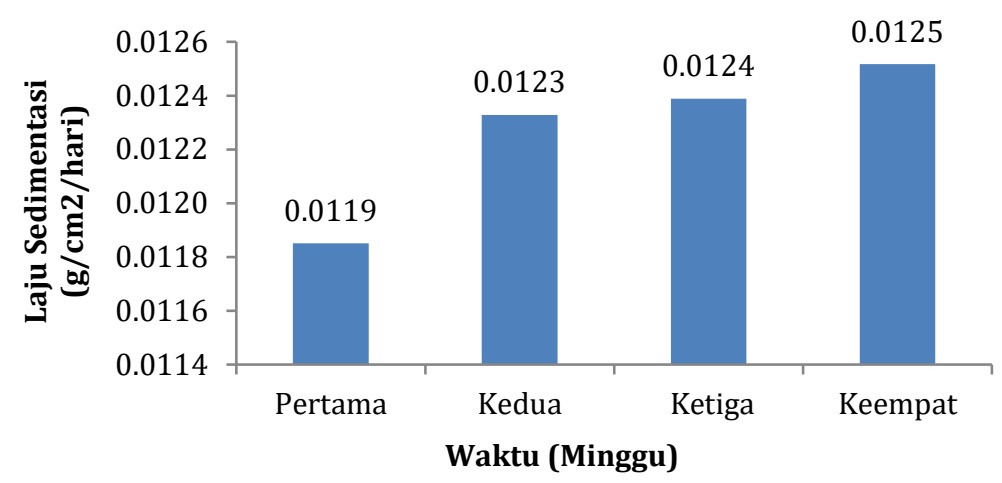

Gambar 4. Laju Sedimentasi Berdasarkan Berat Kering

Laju sedimentasi yang terakumulasi di Perairan Beloreng Kelurahan Tembeling Tanjung dalam berat kering dilakukan perhitungan dalam sebulan sebanyak 30 titik memiliki nilai rata-rata sebagai berikut : Laju sedimentasi di minggu pertama sebanyak 30 titik dengan nilai rata-rata $0,0119 \pm 0,0045 \mathrm{~g} / \mathrm{cm}^{2} /$ hari dengan nilai rata-rata terendah karena pada minggu pertama kondisi di Perairan Beloreng Kelurahan Tembeling Tanjung pada saat itu sangat optimal. Laju endapan sedimentasi minggu kedua sebanyak 30 titik mengalami kenaikan dengan nilai rata-rata 0,0123 $\pm 0,0045$ $\mathrm{g} / \mathrm{cm}^{2} /$ hari, hal ini disebabkan pada minggu kedua mengalami musim penghujan di Perairan Beloreng Kelurahan Tembeling Tanjung. Laju sedimentasi minggu ketiga sebanyak 30 titik mengalami kenaikan dengan nilai rata-rata $0,0124 \pm 0,0045 \mathrm{~g} / \mathrm{cm}^{2} /$ hari. Hal ini disebabkan karena musim penghujan di Perairan Beloreng Kelurahan Tembeling Tanjung sehingga laju sedimentasi mengalami peningkatan. Laju sedimentasi minggu keempat sebanyak 30 titik mengalami kenaikan dengan nilai rata-rata $0,0125 \pm 0,0041 \mathrm{~g} / \mathrm{cm}^{2} /$ hari. Hal ini disebabkan karena musim penghujan di Perairan Beloreng Kelurahan Tembeling Tanjung sehingga laju sedimentasi mengalami peningkatan yang cukup signifikan. Data diatas menunjukkan bahwa setiap minggu selama sebulan nilai rata-rata nya mengalami peningkatan dikarenakan saat minggu pertama cuaca masih optimal, berbeda pada minggu kedua hingga minggu keempat yang pada saat itu cuaca mengalami musim penghujan sehingga terjadinya sedimen erosi bekas lahan pertambangan bauksit masuk keperairan dan mengalami peningkatan yang signifikan.

Nilai rata-rata adalah 0,3668 g/ $\mathrm{cm}^{2} /$ hari. Laju sedimentasi di Perairan Beloreng Kelurahan Tembeling Tanjung masih terkatekategori rendah. Menurut Hidayat et al. (2014) kategori sedimentasi yang tinggi berkisar antara > 50 $\mathrm{g} / \mathrm{cm}^{2}$ hari. Faktor yang mempengaruhi kecilnya laju sedimentasi di Perairan Beloreng Kelurahan Tembeling Tanjung adalah kerapatan lamun. Total kerapatan lamun di Perairan Beloreng Kelurahan Tembeling Tanjung adalah 126,57 tegakan $/ \mathrm{m}^{2}$ yang terkategorikan rapat.

\subsection{Laju Volume Sedimentasi}

Kecepatan akumulasi pada penelitian ini dibedakan menjadi kecepatan volume akumulasi (ml) dan berat akumulasi (gram) persatuan luas permukaan $(\mathrm{cm})$ sediment trap selama 30 hari, dan diambil dalam jangka waktu setiap minggu. Pengukuran laju volume akumulasi menggunakan tabung ukur $25 \mathrm{ml}$ dan diisi air sebanyak $20 \mathrm{ml}$ untuk dilihat volume endapan sedimen yang masuk didalam gelas ukur.

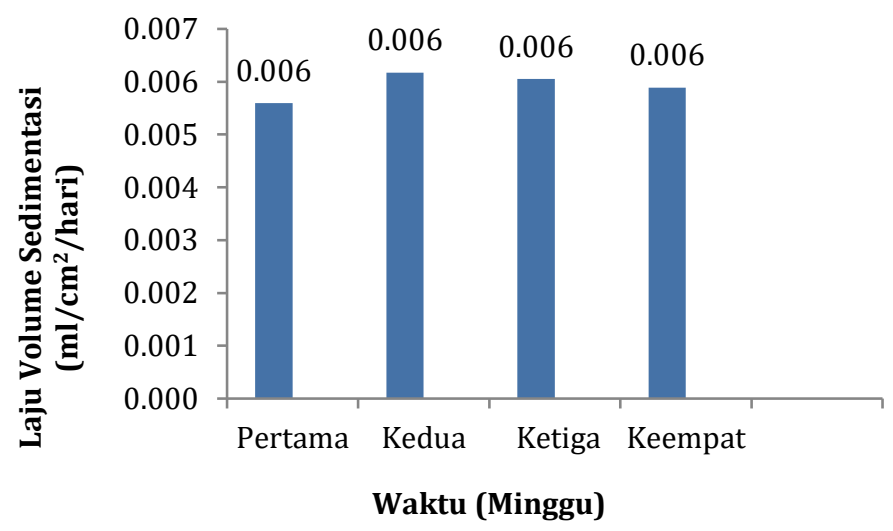

Gambar 5. Laju Volume Sedimentasi 
Hal ini dapat dilihat bahwa data rata-rata perhitungan laju volume sedimentasi selama sebulan penelitian yang hampir sama. Hal ini diduga lokasi penelitian berada pada bekas aktivitas penambangan bauksit. Sebagian besar sedimen fraksinya diperoleh dari aktivitas penambangan. Hal ini dapat dilihat dari warna sedimen yang terdapat di dalam gelas ukur. Perhitungan volume sedimentasi pada 30 titik didapatkan nilai rata-rata adalah $0,1778 \mathrm{ml} / \mathrm{cm}^{2} /$ hari. Menurut Roswaty et al. (2014), volume akumulasi sedimen menggambarkan perairan akan mengakibatkan pada tingginya nilai kekeruhan akibat suspensi dan pengendapan yang akan berdampak pada pendangkalan. Akumulasi akan terus meningkat apabila kondisi vegetasi lamun telah rusak dan diperlukan untuk mengurangi dampak erosi dari darat serta abrasi oleh arus pada pinggir perairan.

\subsection{Hasil Keeratan Semua Variabel}

Principal Component Analysis (PCA) digunakan untuk melihat komponen utama parameter lingkungan mana yang lebih dekat dengan laju endapan sedimen dan kerapatan lamun.

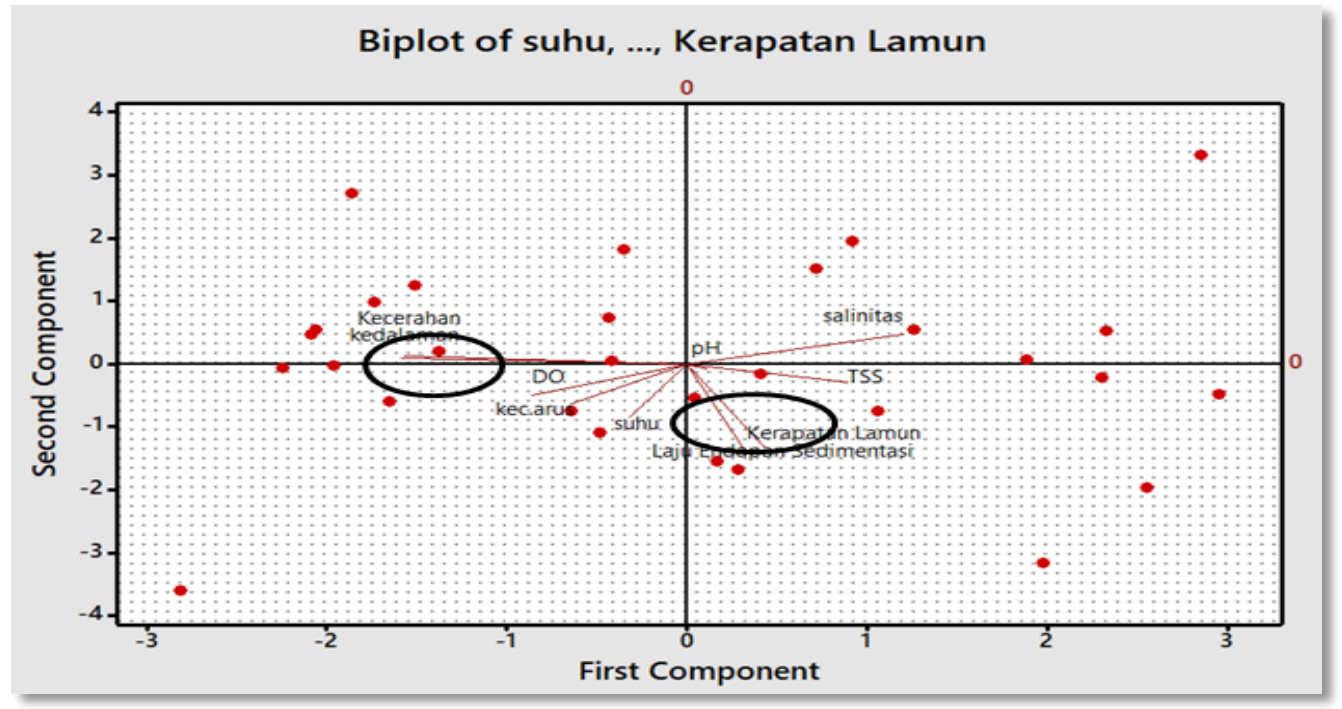

Gambar 6. Hasil Principal Component Analysis (PCA)

Berdasarkan analisis Principal Component Analysis (PCA) yang telah dilakukan pada pengamatan didapatkan bahwa Laju Sedimentasi memiliki hubungan dengan kerapatan lamun dan kecerahan memiliki hubungan dengan kedalaman. Hal ini sesuai dengan pendapat Nursanti et al (2013), menyatakan bahwa kerapatan memiliki pengaruh dan hubungan yang kuat terhadap laju sedimentasi. Hal ini menunjukkan bahwa ada keeratan dan adanya pengaruh laju sedimentasi terhadap kerapatan lamun di Perairan Beloreng Kelurahan Tembeling Tanjung dengan dilakukan PCA.

Kecerahan memiliki Hubungan dengan kedalaman, hal ini sesuai dengan pendapat Pamungkas dan Jaelani (2016) yang menyatakan kedalaman berpengaruh terhadap keberadaan lamun yang memiliki nilai koefisien yang paling besar, kecerahan juga memliki nilai koefisien yang hampir sama, sehingga kecerahan memiliki pengaruh yang hampir sama. Kecerahan yang nilainya negatif, hal itu berarti bila nilai kecerahan masuk ke dalam rentang menurut Peraturan Menteri Lingkungan Hidup, justru membuat wilayah perairan menjadi tidak sesuai bagi habitat padang lamun.

\subsection{Pengaruh laju sedimentasi berdasarkan berat dengan kerapatan lamun}

Hasil analisa regresi didapatkan persamaan nilai $(y=-0,019+0,000 \mathrm{x})$. Adapun nilai koefisien korelasi yang didapat adalah $=0,933$. Menurut Alwi (2013), jika nilai koefisien korelasi berkisar antara 0,80-1,00 maka kekuatan hubungannya bersifat sangat kuat. Hubungan dari laju sedimentasi terhadap Kerapatan Lamun dapat diduga akibat erosi bekas tambang bauksit sehingga perairan tersebut mengalami keruh yang mengakibatkan mengurangi masuknya cahaya matahari sehingga menggangu proses fotosintesis pada ekosistem lamun.

Adapun nilai koefisien determinansi yang diperoleh adalah 0,871 yang berarti bahwa Laju Sedimentasi 87\% dipengaruhi oleh Kerapatan Lamun. Sisanya dipengaruhi oleh faktor lain yang tidak tercakup dalam penelitian ini.

\section{SIMPULAN}

1. Kerapatan lamun di Perairan Beloreng Kelurahan Tembeling Tanjung dikategorikan Rapat.

2. Laju sedimentasi di Perairan Beloreng Kelurahan Tembeling Tanjung $0,3668 \mathrm{~g} / \mathrm{cm}^{2} /$ hari dengan nilai rata-rata menunjukkan adanya peningkatan pada tiap minggu-nya selama sebulan dilakukan penelitian. Nilai total rata-rata volume sebesar $0,1778\left(\mathrm{ml} / \mathrm{cm}^{2} /\right.$ hari) dengan nilai rata-rata perbulan yang sama.

3. Pengaruh lamun terhadap laju sedimentasi di Perairan Beloreng Kelurahan Tembeling Tinggi sangat tinggi mencapai $87 \%$ sisanya dipengaruhi faktor lain yang tidak tercakup dalam penelitian ini. 


\section{REFERENSI}

Azkab, M.H. (1999). Pedoman inventarisasi lamun. Oseana, 24(1): 1-16.

Azkab, M.H. (2000). Struktur dan fungsi pada komunitas lamun. Oseana, 25(3): 9-17.

(DKP) Dinas Kelautan dan Perikanan Kabupaten Bintan. (2011). Profil Kelautan dan Perikanan Kabupaten Bintan http://ppid bintankab.go.id/download/Profil \%20DKP\%20Bintan.pd f, 13 November 2015.

Hidayat, M., Ruswahyuni., \& Widyorini, N. (2014). Analisis Laju Sedimentasi di Daerah Padang Lamun dengan Tingkat Kerapatan Berbeda di Pulau Panjang, Jepara. Management of Aquatic Resources Journal, 3(3): 73-79.

Keputusan Menteri Lingkungan Hidup Nomor 51 Tahun 2004. Baku Mutu Air Laut Untuk Biota Laut.

Keputusan Menteri Lingkungan Hidup Nomor 200 Tahun 2004. Kriteria Baku Kerusakan dan Pedoman Penentuan Status Padang Lamun.

Mariani, Melani, W. R., \& Lestari, F. (2019). Hubungan Bivalvia dan Lamun di Perairan Desa Teluk Bakau Kabupaten Bintan. Jurnal Akuatiklestari, 2(2): 31-37. https://doi.org/10.31629/akuatiklestari.v2i2.994

Nursanti, N., Riniatsih, I., \& Satriadi, A. (2013). Studi Hubungan Kerapatan Vegetasi Lamun dengan Laju Sedimentasi di Perairan Teluk Awur dan Bandengan Jepara Pada Periode Juni-Juli 2012. Journal of Marine Research, 2(3): 25-34.

Pamungkas, M.W.T., \& Jaelani, L.M. (2016). Pemodelan Persamaan Hubungan Kualitas Perairan Menggunakan Citra Landsat 8 untuk Pendugaan Habitat Padang Lamun (Studi Kasus: Pantai Sanur, Bali). Jurnal Teknik ITS, 5(2): 170-175.

Purba, R.R., Lestari, F., \& Kurniawan, D. (2018). Hubungan Kerapatan Lamun dengan Kelimpahan Gastropoda di Perairan Tanah Merah Desa Penaga Kabupaten Bintan. Repository UMRAH.

Putri, P.I., Lestari, F., \& Susiana. (2018). Potensi Sumberdaya Lamun sebagai Pencadangan Kawasan Konservasi di Perairan Beloreng, Tembeling, Kabupaten Bintan. Jurnal Akuatiklestari, 2(1): 14-21. https://doi.org/10.31629/akuatiklestari.v2il.2348

Roswaty, S., Muskananfola, M.R., \& Purnomo, P.W. (2014). Tingkat Sedimentasi di Muara Sungai Wedung Kecamatan Wedung, Demak. Management of Aquatic Resources Journal, 3(2): 129-137.

Santoso, B., Dharma, I.G.B.S., \& Faiqoh, E. 2018. Pertumbuhan dan Produktivitas Daun Lamun Thalassia hemprichii di Perairan Tanjung Benoa, Bali. Journal of Marine and Aquatic Sciences, 4(2): 278-285.

Sari, D.P., Lestari, F., \& Kurniawan, D. (2018). Hubungan Kerapatan Lamun Dengan Kepadatan Bivalvia di Perairan Desa Pengudang. Repository UMRAH.

Shaffai, E.A. (2011). Field Guide to Seagrasses of the Red Sea. IUCN (Internasional Union for Conservation of Nature). Publications Services, Gland, Switzerland. 15(3): 124-220.

Simon, I., Patty., Rifai, H. 2013. Struktur Komunitas Padang Lamun di Perairan Pulau Mantehage, Sulawesi Utara. Jurnal Ilmiah Platax, 1 (4), 177-186.

Surbakti, H. (2012). Karakteristik pasang surut dan pola arus di muara Sungai Musi, Sumatera Selatan. Jurnal Penelitian Sains, 15(1): 35-39.

Syukur, S. (2016). Konservasi Lamun untuk Keberlanjutan Sumberdaya Ikan di Perairan Pesisir Indonesia. Kelautan. 16(1): 56-65. 